\title{
Story-telling Silk Route Collapsing the Walls of Differences: An Analysis on Chitra Banerjee Divakaruni's One Amazing Thing
}

https://doi.org/10.3126/litstud v29i01.39614

\author{
Susmita Talukdar
}

Abstract

The article examines power of narrative/storytelling in developing collective force that would serve as survival strategy for facing catastrophe. In Divakaruni's One Amazing Thing the nine characters, who are trapped by a major earthquake in the basement of a high-rise building of Indian visa office in US, go on telling his/her stories of their past, 'one amazing thing' of their lives that they have never been able to share with anyone. Like a very ancient story telling form e.g. the Panchatantra, stories lead to more stories. One story makes the listeners to muse about how it applies to their lives, and that ultimately leads them coming up with their own stories, the choice of which is influenced by the previous story. In their manner of telling stories, the characters feel strangely bound to each other, though they are so different from each other. It is the incredible power of storytelling that collapses the wall of several tags of identity, and brings together the strangers, who are stuck in one room due to natural disaster. Ironically the story takes place in a visa office that confirms one's identity in terms of his/her nationality, race, ethnicity and similar others. It is a natural disaster that brings people from different origin closer to each other and it is the healing power of narrative/storytelling that dissolves all differences revealing what it means to be human.

In my observation, this year 2015 the conference theme of LAN focuses on two major and interrelated issues about the prospect of literature: how literature can both be universal and specific? The very conference title calls for a detailed analysis in which the implication of 'literary silk road' signals the possibility of literature going beyond the boundaries, marked by geography and culture, and connecting people of differences, while at the same time it also draws our attention to speculate how literature in its liberal motif of 'cultural connectivity' can even highlight the particularities and specificities /differences of culture. In the present context of the period, standing at the cross roads of global and local, and of divergence, the conference theme seems to be contemporary and thus appropriate. In my approach to address the conference theme I have chosen Chitra Banerjee Divakaruni's 2009 novel One Amazing Thing which is set in the post 9/11 United State. Through this novel I intend to examine what it means for a literary artist to be both universal and specific at the same time? What ideological vision has shaped Banerjee's poetics? What narrative strategy the author has taken to fulfill both her poetics and politics? It has become very crucial now with the ever changing scenarios of the surroundings to determine not only the role of writers but also that of the readers. As a reader, therefore my query is what literary trope the author has used to 
determine her 'universality' as a literary artist, and how at the same time she has maintained her 'specificity' as an Asian American author? As an artist the author has her confidence in the power of her narrative/story telling that empowers people during crisis, and as a responsible custodian of her culture she has her faith in the rich resources of her heritage which she collects from her childhood experiences of growing up with listening to stories from her grandfather. The most puzzling question that makes me critical is about the authorial intention. Why is it an Indian Consulate office that the author has chosen for the setting of her novel? Why has she chosen India as the destination of her characters? In her authorial design of the plot though Banerjee has offered her explanation through the stories of each character, in my critical observation I think it is her typical Indian heritage that nurtured her spiritual and cultural development as a writer, and that has shaped both her poetics and politics. In my paper I will show how Banerjee, as a gifted story teller has been able to reveal the rich dimension of life that confirms what it is to be human, irrespective of one's race, gender, class, and similar other socio cultural tags, and how at the same time, she remains specific to her original sensibilities as an Asian American writer. Thus in performing both, the author appeals for her universalist motto as a literary artist, and adds to the multicultural policies of US contributing her Asian American specificity to the enrichment of American identity.

In her interview with Metka Zupancic Banerjee narrated how her own experience of Hurricana Rita inspired her to write One Amazing Thing. She told that they had to evacuate Houston because of the disaster, and there was a lot of panic. She also told that in the novel she wanted to explore the 'spiritual question' of what one does if such situation arises. She went on saying, ". If I am in a situation of true danger where the primal urge for survival kicks in, would I be able to rise to a level of compassion? Or would I say 'survival at any cost'? How would we learn to move from one end of the spectrum to the other?"

This 'primal urge for survival' during catastrophe has become the most penetrating question for the author. What survival strategy can be implemented? How as an impartial artist she should indicate an exit/safe journey that would bring welfare not only for an individual but also for the community? For the author it is her story telling strategy that would bring solace for the victims. The author says that she has strong conviction in the power of storytelling that transforms the teller as well as the listener. She says in the same interview,

... my grandfather was a great oral story teller. In my childhood, I would go spend my summer holidays with him in a little village, where at that time there was no electricity and no running water. I thought it was quite a magical place. Every evening he would light a kerosene lamp. and he would bring all of us cousins together. He told us stories out of her epics and out of her fairytales and folktales. I think I have thus developed a great love for the epic stories and the folktale tradition. I have tried to interweave much of it into my work, often in a modern context. (90)

In this novel Banerjee has attempted to bring things together both from her heritage, by going back deep into the ancient heritage of Indian literature, and also out of her experience of living in a multicultural society.

There are nine characters in the novel who are of different sociocultural and economic background, and also are of different perspectives: Mangalam and 
Malathi-two visa officers, Jiang, a Chinese- Indian woman in her last years, her talented, teenaged, granddaughter Lily, Cameron, an African-American exsoldier, Tarique, a young Muslim boy of about 25, an enraged and bitter elderly white Couple, Mr. and Mrs. Pritchett, and Uma, an Indian American girl, puzzled by her parent's sudden decision of settling down in Kolkata after 20years of living in America. These people are trapped by a major earthquake in an Indian Visa office in one unidentified city of US. There is no way of escape, and they must make the best of their circumstances. The building collapses around them; and there is no rescue operations, though people are eagerly waiting for it. With very little food, dwindling oxygen, rising flood water, and no electricity or phone service, people go on panicking, cursing each other, and even fighting. There is much agitation in the minds of the characters; they doubt each other as they are so different from each other. When the situation gradually starts turning from bad to worse Uma comes up with her idea, and says, " We can each tell an important story from our lives." There are a lot of arguments and counterarguments on her suggestion, and Uma persists, "Everyone has a story. . . . I don't believe anyone can go through life without encountering at least one amazing thing" (OAT 65). She also sets down rules, ". . . no interruptions, no questions, and no recriminations, especially by family members. Between stories, they would take breaks as needed" (67). Now the characters go on telling their stories, which they have never shared with anyone. One story makes the listeners to muse about how it applies to their lives, and that ultimately leads them coming up with their own stories, the choice of which is influenced by the previous story.

Banerjee has exposed the typical cultural 'traits' of her characters not just by describing their physical features and dresses, but also through their 'stories', each tells to others, which remarkably distinguish one another. Mangalam and Malathi are Indian in origin, the rests are of many different races, ages, and of truly different socioeconomic background. Malathi, the lady officer of the Consulate office, who is from Coimbatore, feels uncomfortable in sweatshirt, though it covers more of her body than her "midriff-baring blouse and thin shari"; the narrative voice says, "the ways in which cultural habits operated were mysterious" (34). Mr. Mangalam, the visa officer is a typical Tamil with "swashbuckling mustache, and designer sunglass" (16); he was provided the best of everything by his poor parents because he was a son after three daughters in the family, and that the astrologer, after examining his horoscope, had forecasted that he would rise high. Lily, the granddaughter of Jiang is second generation American, who represents a modern American youth with pierced eyebrows, tattoos, black lipstick, and black dress; she likes to draw her parents' attention by doing things what they do not like. Tariq Husein, a bearded young Muslim man, is another second generation American; he is angry with the new America after 9/11 incident, and he never forgets to stick to his routine prayers. Cameron is a lanky African American, who is almost in his fifties with 'shaved head.' The author describes him as ". . .the sharp, ascetic bones of his face gave him an ageless, monkish appearance, though the effect was somewhat undercut by the sparkly studs in his ears" (4). Uma is an American Indian girl, but she can hardly be described as an Indian, as her 'hip- hugging jeans' and 'American impatience' disclose her western upbringing.

The stories told by these characters distinctly reveal their cultural 
identities; e.g. Jiang's story of lost love focuses on how Chinese people associate naming of things with luck ; their shoe store of New Market in Calcutta was named by herself as FENG'S FINE FOOTWEAR, which for her grandmother was an 'arrogant declaration' , and that would attract 'bad luck.' Her love affair with a Bengali boy did not materialize as the marriage between a devout Hindu and staunch Bengali with a Chee-nay (italics mine) heathen, could not be thought of in those days. In their utmost attempt of breaking up the relationship between the lovers Mohit's mother and Jiang's grandmother started praying to their different deities; the Hindu mother by offering 'hibiscus garlands' to Goddess Kali at 'Kalighat ' temple, and the heathen grandmother, by light joss sticks at Kuan Yin's shrine. Malathi's story reveals how much difficult it is for the girls of her community to get married without dowry; Tarique is confused of what he should do; Farah, his beloved, wants him to go back to India; even his parents too want his company there after the things that had happened with his 'abba' due to their religious status, caused by the effect of 9/11. The narrative voice reflects Tarique's dilemma "This was my country. I was an American" (131). Uma is not ready to accept her parents' sudden decision to settle in Kolkata, though her mother goes on explaining in pleasant tone about a different and new India, 'shinning; ' how happy they are now in Kolkata in visiting childhood friends or attending 'Rabindra Sangeet concert ' $(5,6)$.

By making her characters telling their stories at the most crucial moments of their lives, as they are not sure how long they will survive, Banerjee seems to have made them face their own inner selves, which makes them move from one spectrum of life to another. They learn to look to other dimension of life which is so full of possibility. Jiang confesses later how much love she had for her husband, which she realized when her husband was in his death bed. By telling her story, Mrs. Pritchett seems to have discovered a latent 'truth,' and she realizes that she too had been responsible for the development of bitter understanding with her husband. Cameron, who was always haunted by his guilty consciousness, reveals in his story how he has been destined for Seva, one orphan girl of India. In telling her story Uma is struck with her guilty consciousness of not telling the truth of once her father's decision to divorce her mother. She did not realize, as she says in her story, " until this earthquake, until today - that my withholding was a worse kind of betrayal, a betrayal of the self" (206). In telling their stories to each other it is not just the characters shares their private tells but they come to recognize themselves with many things of their inner selves, those remained unfolded. It is as if the devastating earthquake has revealed their true selves to them.

The title of the novel One Amazing Thing thus denotes the amazing power of narrative, that even exposes the most amazing thing of love, as Jiang notes, in her confession of love for her husband whom at first she did not love at all: "That's what is amazing. We can change completely and not recognize it. We think terrible events have turned us into stone. But love slips in like a chisel----and suddenly it is an axe, breaking us into pieces from the inside" (86). The author has said "Writing must come out of what we know, what we feel.... But ultimately it must transcend all that to reach across time and space and memory to touch those who have never - and who will never - live as we have lived. What else is literature for? Because if it is only the specifics of a culture we want to record, surely a sociologist or an 
anthropologist could do it better" (qtd. in Lamor 5).

An author's credit is acknowledged in his/her narrative skill, how it awakens self consciousness of a reader, how it persuades a reader to participate actively in the writer's writing process so that a text becomes writer/reader venture. Grewal has asserted how the saving power of narrative widens reader's sensibilities, and how a narrative demands reader's active participation to make out the meaning of a text. She points out that in the ways of reading she realizes "the saving power of narrative, its capacity to open a door, to point out the fire and the fire escape----in short, the profound work that narrative can do for the social collective and the work that such a narrative in turn demands from us" (x). Thus by dealing with people belonging to different cultures and societies, it is Banerjee's story telling silk route that collapses the wall of differences, and connects one another. What remains is the harmonious tune of humanity which is unique in its diversity.

\section{Works Cited}

Divakaruni, Chitra Banerjee. One Amazing Thing. New Delhi: Penguin Books, 2010. Print.

Grewal, Gurleen. Circles of Sorrow, Lines of Struggle: The Novels of Toni Morrison. Baton Rouge: Louisiana State UP, 1998. Print.

Lemor, Lisa. Fractured Identity: The jagged Path of Diaspora in Chitra Banerjee Divakaruni's The Mistress of Spices. M.A. Thesis. Minnesota State University, 2011. Print.

Zupancic, Metka. "The Power of Storytelling: An Interview with Chitra Banerjee Divakaruni." Contemporary Women's Writing 6.2 (2012): 85-101. Web. 10 Jan. 2012. 